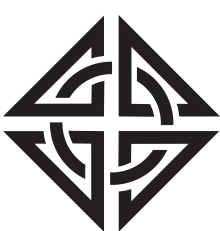

SCIENTIA
Sharif University of Technology

Scientia Iranica

Transactions C: Chemistry and Chemical Engineering

www.scientiairanica.com

\title{
Degradation of furfural in contaminated water by titanium and iron oxide nanophotocatalysts based on the natural zeolite (clinoptilolite)
}

\author{
Z. Esmaili, A.R. Solaimany Nazar* and M. Farhadian \\ Department of Chemical Engineering, Faculty of Engineering, University of Isfahan, Isfahan, Iran. \\ Received 14 June 2015; received in revised form 2 December 2016; accepted 24 April 2017
}

\author{
KEYWORDS \\ Advanced oxidation \\ process; \\ Contaminated water; \\ Furfural; \\ Nano photocatalyst; \\ Titanium oxide.
}

\begin{abstract}
In this study, the performance of advanced oxidation process using titanium and iron oxides based on the natural clinoptilolite zeolite $\left(\mathrm{TiO}_{2} / \mathrm{Fe}_{2} \mathrm{O}_{3} /\right.$ Clinoptilolite) as a nanophotocatalyst was studied, and the effects of various factors on the furfural degradation, such as $\mathrm{pH}$, dosage of catalyst, initial concentration of furfural, and contact time, were examined. The co-precipitation method was applied for the synthesis of the nanophotocatalyst. The SEM and XRD analyses showed a uniform distribution of titanium dioxide and iron nanoparticles on the zeolite. The furfural degradation could successfully happen at neutral to alkaline solutions. Moreover, increasing the amount of catalyst from 0.5 to $1.5 \mathrm{~g} / \mathrm{L}$ does not have significant effects on the degradation efficiency. By enhancing the initial concentration of furfural from 75 to $300 \mathrm{mg} / \mathrm{L}$, the rate of degradation decreases. The maximum efficiency of $98 \%$ could be achieved for $75 \mathrm{mg} / \mathrm{L}$ solution by using $1.5 \mathrm{~g} / \mathrm{L}$ catalyst in $\mathrm{pH}$ equal to 8 within 120 minutes.
\end{abstract}

(C) 2017 Sharif University of Technology. All rights reserved.

\section{Introduction}

Due to increased wastewater production and variety of pollutants, precautionary actions are essential for the environment protection. One of the main sources of water pollution is release of chemical compounds from petrochemical industries, oil refineries, and chemical plants into the environment. Most of these chemicals are non-biodegradable and cannot be removed through biological systems. Nevertheless, they have toxic effects on living organisms, such that many aromatic and cyclic organic compounds, such as phenol and furfural, have these properties. Furfural, a toxic and hazardous chemical with adverse effects on living organisms, has

\footnotetext{
*. Corresponding author. Tel.: + 9831 3r934027; Fax: + 983137934031

E-mail addresses: zakie.esmaeily@yahoo.com (Z. Esmaili); asolaimany@eng.ui.ac.ir (A.R. Solaimany Nazar); m.farhadian@eng.ui.ac.ir (M. Farhadian)
}

been exceeding in the amount in industrial wastewater, and therefore should be specifically considered in treatment processes [1-3]. Furfural is widely used in various processes such as extraction, paper mills, and separation of colors from other hydrocarbons. Advanced oxidation processes generally include the formation and the use of strong oxidizing agents such as hydroxyl radicals. These processes are relatively new and have been used in purification of different industrial waste waters [4]. These processes can break down the toxic chemicals and compounds that are resistant to biological treatment methods in the environment. Chemical oxidation processes have received much attention in recent years [1-6]. In these types of reactions, UV (Ultra Violet) irradiation could be used solely or combined with other oxidizing agents and mineral catalysts. Some of these chemical oxidation processes in the degradation of furfural have been reported as effective in the removal of various chemical complexes [1-3,7-9]. 
In this regard, Faramarzpour et al. used titania nano-particles for the photocatalytic degradation of furfural in a floating-bed photoreactor. According to their results, a furfural concentration reduction of more than $95 \%$ was observed within 2 hours [8]. Nezamzadeh and Moeinirad removed the furfural by the NiS-clinoptilolite photocatalyst. The NiS particles out of the zeolite framework did not show significant degradation efficiency [9]. Ahmadi et al. used $\mathrm{TiO}_{2}$ nanoparticles immobilized on a glass support, and their results demonstrated that the furfural photocatalytic reaction in 140 minutes led to the production of maleic and tartaric acids as intermediates [6]. Hosseini et al. immobilized $\mathrm{TiO}_{2}$ on leca (light weight expanded clay aggregate) granules for photocatalytic degradation of furfural in a batch reactor. Based on their research, the rate of furfural degradation was positively affected by using UV radiation [10]. Zhang et al. synthesized strontium titanate microtubules and investigated their photocatalytic activity for degradation of furfural in aqueous solutions. As a result, they found that the photocatalytic capacity of synthetic strontium titanate microtubules under the condition of calcinations temperature at $1000^{\circ} \mathrm{C}$ is the highest [11]. MousaviMortazavi and Nezamzadeh used supported iron oxide onto an Iranian clinoptilolite as a heterogeneous catalyst for photodegradation of furfural in a wastewater sample. Their results have shown that the efficiency of the process significantly depends on the experimental factors [12]. Veisi et al. investigated photocatalytic degradation of furfural in an aqueous solution by $\mathrm{N}$ doped titanium dioxide nanoparticles. In their research, the efficiency of furfural removal was found to increase with increased reaction time, nanoparticle loading, and pH, whereas the efficiency decreased with increased furfural concentration [13]. Soltan et al. used nano $\mathrm{TiO}_{2} / \mathrm{SiO}_{2}$ deposited on cementitious materials for enhancement of photocatalytic degradation of furfural and acetophenone in water media. The results showed that the removal of these pollutants from water using mentioned photocatalyst under UV irradiation was performed with greater efficiency, which does not require an additional separation stage to recover the photocatalyst. Therefore, it would be applicable for use in industrial wastewater treatment at room temperature and atmospheric pressure within the optimized $\mathrm{pH}$ range [14].

These processes are perfect to be substituted with filtering, adsorption, reverse osmosis, and other methods that are conventionally applied to remove the nonbiodegradable chemicals. There are various nanoparticle immobilization techniques for synthesis of photocatalysts including sol-gel, co-precipitation, hydrothermal, as well as shrinking methods [1]. Impregnating of catalyst onto suitable supports is a strategy that has been used to enhance the photodegradation efficiency.
Among the supports, zeolites are the most famous candidates due to their good properties such as high cation exchange capacity, high adsorption capacity, etc. High cation exchange capacity prevents aggregation of supported catalysts that increases effective surface area of the catalyst. High adsorption capacity of supports can be a cause for bringing molecules of pollutant near the catalyst, and hence photodegradation efficiency tends to increase [15]. Due to these advantages, we have used a cost-effective natural zeolite as a good support in our experiment.

The main objectives of this research include studying the effect of a new and efficient synthetic iron and titanium nanophotocatalyst based on the natural and cost-effective zeolite (clinoptilolite) on the degradation of the furfural for the first time and evaluation of the factors effect, such as the contact time, $\mathrm{pH}$, the initial concentration of furfural, and the amount of catalyst on the destruction of furfural. The XRD (X-Rag Diffraction) and the SEM-EDX (Scanning Electron Microscope-Energy Dispersive Spectroscopy) analyses are employed to investigate the composition and morphology of the photocatalysts.

\section{Materials and methods}

\subsection{Materials}

Natural clinoptilolite was obtained from Semnan in the northeastern region of Iran. Furfural, $\mathrm{TiCl}_{4}, \mathrm{FeCl}_{3}$, sodium hydroxide, sulphuric acid, hydrogen peroxide, and all other chemicals in analytical grades were obtained from Merck, Germany. Moreover, the water used throughout the experiments was both distilled and deionized. The $\mathrm{pH}$ of the solutions was adjusted by sodium hydroxide and sulphuric acid solutions when needed.

\subsection{Experimental setup}

The photodegradation experiments were performed by a batch photocatalytic reactor system. The system was a cylindrical pyrex-glass cell with $250 \mathrm{ml}$ capacity. Irradiation experiments were performed using a medium pressure Hg UV lamp 8W $(6 \times 212 \mathrm{~mm}, 254$ nm, Philips, Germany) placed in a quartz tube with one end tightly sealed by a teflon stopper. The lamp and the tube were immersed in the photoreactor cell. A magnetic stirrer was used continuously to guarantee sufficient mixing of the solutions. The reaction was carried out at room temperature. Cooling water was introduced to the jacket, surrounding the photoreactor for cooling and maintaining constant temperature during the experiments.

\subsection{Analytical tests}

\subsubsection{Photocatalytic tests}

The furfural concentration in the samples was measured by an UV spectrophotometer (Jasco, V-570, 
Japan). For this purpose, the samples were analyzed at maximum wavelength of $275 \mathrm{~nm}$ by a quartz cell (Starna, England). The Chemical Oxygen Demand (COD) measurements were carried out by a COD analyzer of Lovibond (England) based on the standard methods for the examination of water and sewage [16]. The degradation of the furfural samples in a number of experiments was also monitored by high-performance liquid chromatography (KNAUER, manager 5000, Germany). The XRD pattern of samples was prepared using a Bruker diffractometer (D8 Advance) with a Nifiltered copper radiation $(K \alpha=1.5406)$ in $2 \theta$ range of $6-80^{\circ}$. In addition, the surface morphology of samples was determined using a Philips XL30 Scanning Electron Microscope (SEM). The EDX analysis was also taken for the chemical analysis of the samples using the ALS2300C model, Germany. The weight percent of compounds in the samples was measured by X-Ray Fluorescence (XRF) analyzer (Bruker, S4PIONEER, Germany).

\subsection{Preparation of zeolite sample}

For preparation of zeolite, first, impurities of the raw zeolite samples were separated by mechanical methods and the zeolite was grounded by a mortar and pestle. Then, the obtained powder was screened by ASTM (American Society for Testing and Materials) standard sieves of 200 to 400 micron sizes. After removal of the impurities, the samples were washed by deionized water, and then dried in ambient temperature $\left(25^{\circ} \mathrm{C}\right)$ to get prepared for the next steps.

\subsection{Immobilization of titanium and iron oxides on the natural zeolite (clinoptilolite)}

To immobilize titanium and iron oxide nanoparticles on the natural zeolite, first, the zeolite powder $(25.4 \%$ wt/wt of the photocatalyst) was prepared by mixing it with distilled water and heating to $70^{\circ} \mathrm{C}$. For the synthesis of the nanophotocatalyst, the solutions of $\mathrm{TiCl}_{4}\left(71 \%\right.$ wt/wt) and $\mathrm{FeCl}_{3}(3.6 \%$ wt/wt) were simultaneously added to the zeolite powder drop-wise while mixing together. Meanwhile, the $\mathrm{pH}$ of the suspension was adjusted at 2.0 for producing a steady solution. Then, the mixture was heated at the same temperature for 4 hours with vigorous shaking until the solvent was evaporated. Afterwards, the solution was placed still for 12 hours until the conversion of $\mathrm{TiCl}_{4}$ and $\mathrm{FeCl}_{3}$ into their oxides was completed. The products were repeatedly washed with deionized water, and then dried in an oven at $80^{\circ} \mathrm{C}$ for 2 hours. Finally, the calcination process was performed in a Muffle furnace at $400^{\circ} \mathrm{C}$ for 2 hours [17].

\subsection{The photocatalytic activity}

The degradation efficiency was determined by obtaining the absorbance of the solutions before and after

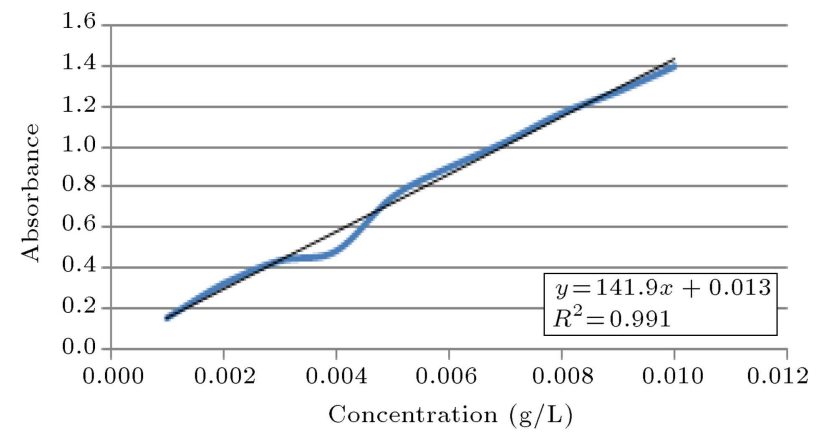

Figure 1. Calibration curve of furfural.

photodegradation experiments at the wavelength of maximum absorption (275 $\mathrm{nm}$ ) of furfural using a UV-Visible spectrophotometer. At this wavelength, a standard graph of absorbance versus the concentration of furfural calibration curve was prepared that is shown in Figure 1. This graph shows a linear variation up to $0.01 \mathrm{~g} / \mathrm{L}$ concentration. Therefore, the samples with higher furfural concentration were diluted with distilled water, when needed, to lessen the concentration below $0.01 \mathrm{~g} / \mathrm{L}$ for accurate determination of the furfural concentration. Calibration equation:

$$
\text { absorbance }=0.141 C_{F}+0.013, \quad r^{2}=0.991 .
$$

\subsection{Experimental procedure}

In each of the experiments, a certain amount of nanophotocatalyst was added into a furfural solution with specified concentrations. Also, for increasing the amount of radical hydroxyls and the efficiency, $0.4 \mathrm{~g} / \mathrm{L}$ $\mathrm{H}_{2} \mathrm{O}_{2}$ was added into the solution. Then, the prepared solution was exposed to UV irradiation to determine the destruction efficiency after a specified period of time.

The Minitab software version 16 was used for optimization of experiments due to the multiplicity of experiments.

\subsection{Confirmatory tests}

A furfural degradation measurement by applying spectrophotometer was compared to the HPLC (HighPerformance Liquid Chromatography) and the COD analysis results on a $0.1 \mathrm{~g} / \mathrm{L}$ furfural sample.

\section{Results and discussion}

\subsection{Characterization}

\subsubsection{Chemical composition of clinoptilolite}

The XRF results of the chemical composition of purified natural clinoptilolite are presented in Table 1. $\mathrm{Si} / \mathrm{Al}$ ratio is 4.14 for clinoptilolite, which is within the ranges reported in literature $[18,19]$. The agreement between results of previous studies and the current obtained results proves that the applied zeolite is clinoptilolite $[9,17]$. The results also show that the 
Table 1. The XRF results of natural clinoptilolite and the synthesized photocatalyst.

\begin{tabular}{|c|c|c|}
\hline Compound & $\begin{array}{c}\text { Natural zeolite } \\
\text { concentration } \\
(\% \mathrm{~W} / \mathrm{W})\end{array}$ & $\begin{array}{c}\text { Photocatalyst } \\
\text { concentration } \\
(\% w t / w t)\end{array}$ \\
\hline $\mathrm{SiO}_{2}$ & 72.13 & 29.83 \\
\hline $\mathrm{Al}_{2} \mathrm{O}_{3}$ & 10.50 & 4.24 \\
\hline $\mathrm{CaO}$ & 1.94 & 0.128 \\
\hline $\mathrm{K}_{2} \mathrm{O}$ & 1.77 & 0.549 \\
\hline $\mathrm{Fe}_{2} \mathrm{O}_{3}$ & 1.68 & 4.27 \\
\hline $\mathrm{Na}_{2} \mathrm{O}$ & 1.66 & 0.705 \\
\hline $\mathrm{MgO}$ & 0.878 & 0.206 \\
\hline $\mathrm{TiO}_{2}$ & 0.220 & 53.53 \\
\hline $\mathrm{SrO}$ & 0.209 & 0.020 \\
\hline $\mathrm{SO}_{3}$ & 0.140 & 0.11 \\
\hline $\mathrm{ZnO}$ & - & 0.012 \\
\hline $\mathrm{Cl}$ & - & 0.73 \\
\hline $\mathrm{BaO}$ & 0.058 & - \\
\hline $\mathrm{MnO}$ & 0.033 & - \\
\hline $\mathrm{ZrO}_{2}$ & 0.022 & - \\
\hline $\mathrm{CuO}$ & 0.018 & 0.028 \\
\hline $\mathrm{Rb}_{2} \mathrm{O}$ & 0.011 & - \\
\hline LOI & 8.55 & 5.597 \\
\hline Total & 99.82 & 99.95 \\
\hline
\end{tabular}

molar ratio $\left(\mathrm{Fe}_{2} \mathrm{O}_{3} / \mathrm{TiO}_{2}\right)$ of 6 equaling $4 \%$ (wt/wt) of $\mathrm{Fe}_{2} \mathrm{O}_{3}$ in the catalyst was successfully achieved, and a novel photocatalyst was obtained.

\subsubsection{XRD patterns}

The XRD results of clinoptilolite and the synthesized catalyst show similar diffraction peaks, indicating that the zeolite structure did not change due to incorporation of $\mathrm{TiO}_{2}$ and $\mathrm{Fe}_{2} \mathrm{O}_{3}$ particles. However, some differences, such as broadening of the diffraction peaks, an increase or decrease in the intensity of some peaks, and the shift in the position of the peaks to slightly lower angles are observed in the spectra, particularly in $2 \theta$ range of $20-40^{\circ}$. The XRD pattern of the natural zeolite demonstrates the diffraction peaks of $2 \theta=11.35,13.01$, and 26.1 , similar to those reported in previous studies [20]. In the XRD pattern of the nanophotocatalyst, the characteristic peak of anatase $\mathrm{TiO}_{2}$ corresponding to $2 \theta=25.6$ can be seen. Due to the low amount of $\mathrm{Fe}$ in the catalyst structure, there is no peak related to it in the XRD pattern. In fact, the intensity of the peaks in the catalyst composite decreases with respect to that of clinoptilolite. This decrease in intensity can be related to the presence or incorporation of the nanoparticles inside the structure. These changes in the relative intensities of the clinoptilolite peaks were found in the XRD pattern after co-

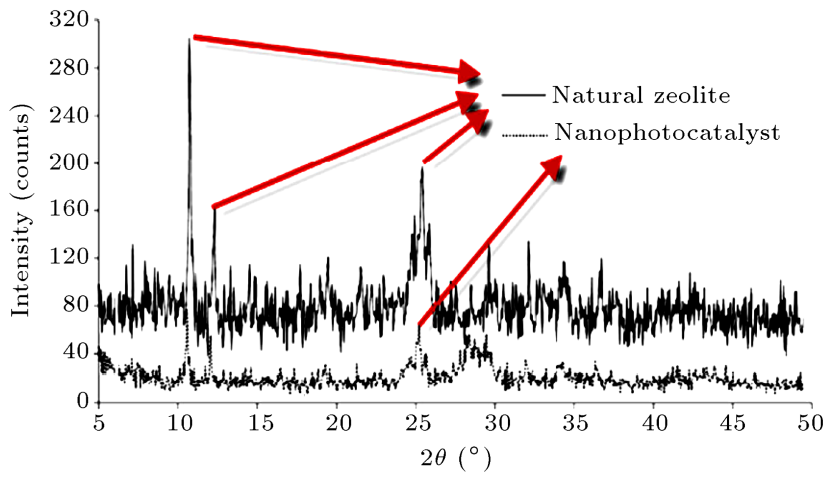

Figure 2. The XRD patterns of the used clinoptilolite and the used nanophotocatalyst.

precipitation. The XRD patterns of the used natural clinoptilolite and photocatalyst are shown in Figure 2. The similar result was also reported by $\mathrm{Li}$ et al. and Wang et al. [17,21].

\subsubsection{SEM-EDX analysis}

The surface morphology of zeolite and the synthesized catalyst was determined through SEM images and their chemical structure was determined by the EDX analysis of the samples which are presented in Figure 3. The crystallites of the unloaded zeolite have very welldefined layers as in the crystals. The SEM image of the loaded samples shows the same crystals, indicating that the zeolite crystallites are not affected by $\mathrm{TiO}_{2}$ and $\mathrm{Fe}_{2} \mathrm{O}_{3}$ loadings. The results of the EDX spectra confirm the loadings of $\mathrm{TiO}_{2}$ and $\mathrm{Fe}^{3+}$ particles on the zeolite matrix. The similar results were reported by Wang et al. [17].

\subsection{Catalytic activity}

A set of experiments was carried out without UV irradiation and $\mathrm{H}_{2} \mathrm{O}_{2}$ addition in the presence of the catalyst to determine its surface adsorption potential. Based on these experiments, the adsorption of furfural by synthesized nanophotocatalyst is negligible. The degradation kinetics of furfural was fitted with a polynomial relation:

$$
C_{F}=0.002 t^{2}-1.413 t+159
$$

where $C_{F}$ represents the final furfural concentration at time $t, r^{2}=0.97$.

\subsubsection{Optimum conditions of the designed catalyst}

In this study, first, the optimum ratio of iron to titanium dioxide and hydrogen peroxide dosage was found through Taguchi design. The levels of the parameters are presented in Table 2. To find the optimum ratio of $\mathrm{Fe}_{2} \mathrm{O}_{3} / \mathrm{TiO}_{2}$ in the catalyst, $0 \%$, $3 \%, 6 \%, 7 \%$, and $100 \%$ ratios of $\mathrm{Fe}_{2} \mathrm{O}_{3} / \mathrm{TiO}_{2}$ in the presence of zeolite were prepared in which $0 \%$ is pure $\mathrm{TiO}_{2}$ and $100 \%$ is pure $\mathrm{Fe}_{2} \mathrm{O}_{3}$ on the clinoptilolite. Likewise, to find the optimum amount of hydrogen 

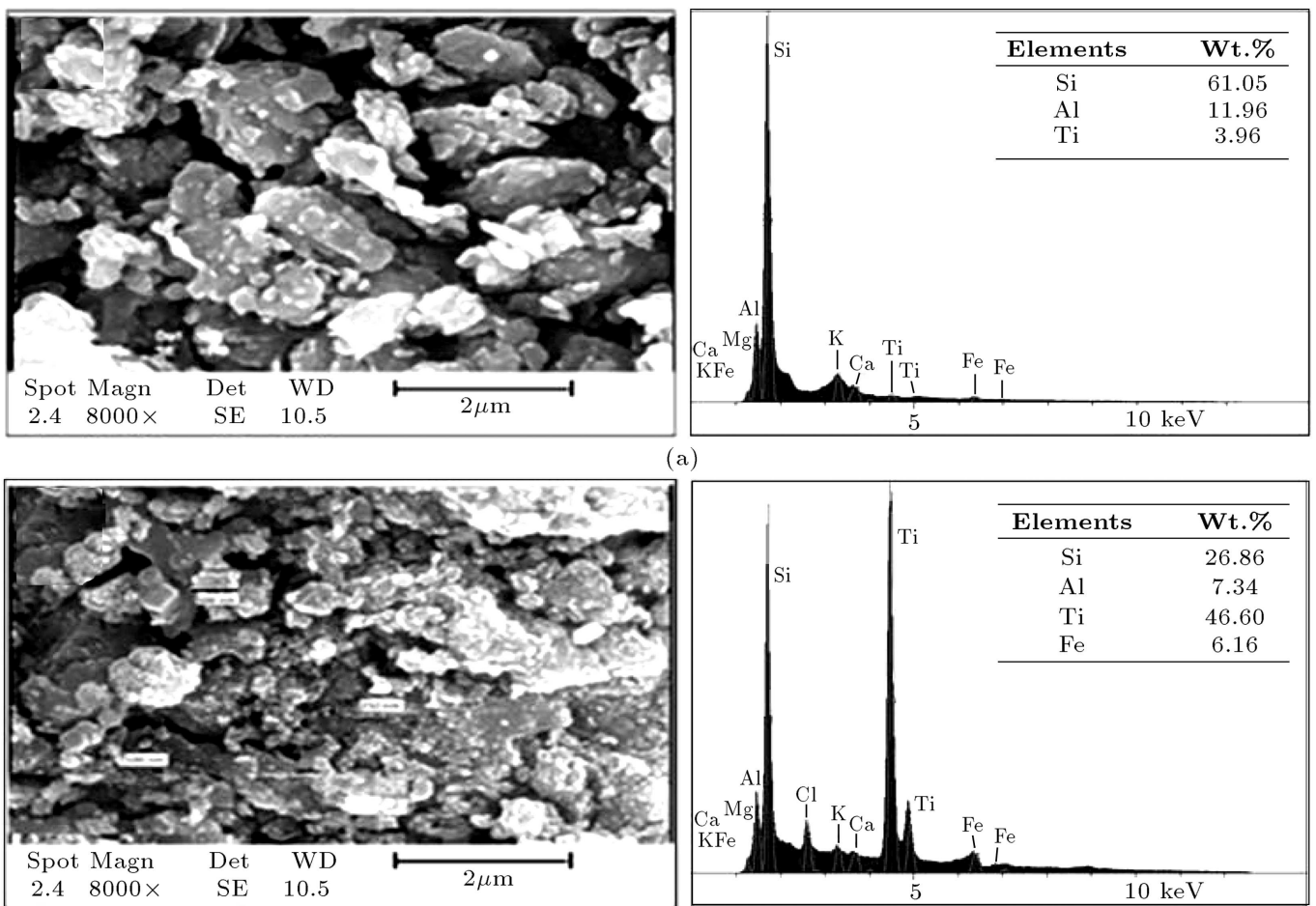

(a)

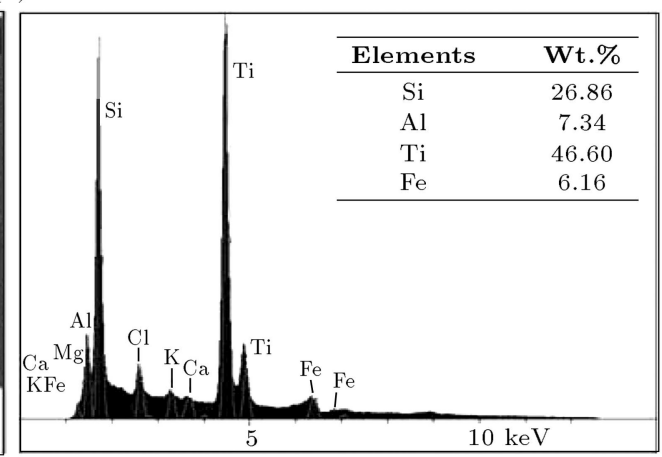

(b)

Figure 3. The SEM images and the EDX spectra of (a) the zeolite and (b) the catalyst.

Table 2. The levels of the catalyst type and the amount of $\mathrm{H}_{2} \mathrm{O}_{2}$.

\begin{tabular}{cc}
\hline $\begin{array}{c}\text { Type of the } \\
\text { catalyst }\end{array}$ & $\begin{array}{c}\text { Amount of the } \\
\mathbf{H}_{2} \mathbf{O}_{2}(\mathbf{g} / \mathbf{L})\end{array}$ \\
\hline $\mathrm{TiO}_{2}$ & 0 \\
$3 \%$ & 0.075 \\
$6 \%$ & 0.15 \\
$7 \%$ & 0.3 \\
$\mathrm{Fe}_{2} \mathrm{O}_{3}$ & 0.4 \\
\hline
\end{tabular}

peroxide, different concentrations of $0,0.1,0.2,0.3$, and $0.4 \mathrm{~g} / \mathrm{L}$ for $\mathrm{H}_{2} \mathrm{O}_{2}$ were tested. Moreover, to examine higher hydrogen peroxide dosages, the concentrations of $0.4,0.55$, and $0.7 \mathrm{~g} / \mathrm{L}$ were also tested. In all experiments, the test time was fixed at 2 hours based on previous studies [1,9], and the initial concentration of furfural was $0.3 \mathrm{~g} / \mathrm{L}$. The degradation efficiency curves of furfural solution with catalysts in different dosages of $\mathrm{Fe}_{2} \mathrm{O}_{3} / \mathrm{TiO}_{2}$ are shown in Figure 4. It can be observed that by utilizing $\mathrm{TiO}_{2}$ as a catalyst in the absence of iron ions, minimum value of the destruction efficiency is achieved. With increasing the iron ion/titanium dioxide ratio, the destruction efficiency of furfural increases. In the molar ratio of $6 \%$, the highest efficiency is achieved. Then, the efficiency decreases as the iron concentration increases to $7 \mathrm{~mol} \%$. When the catalyst is formed of pure iron oxide and clinoptilolite, the degradation is more efficient compared to the molar ratio of $3 \%$. This

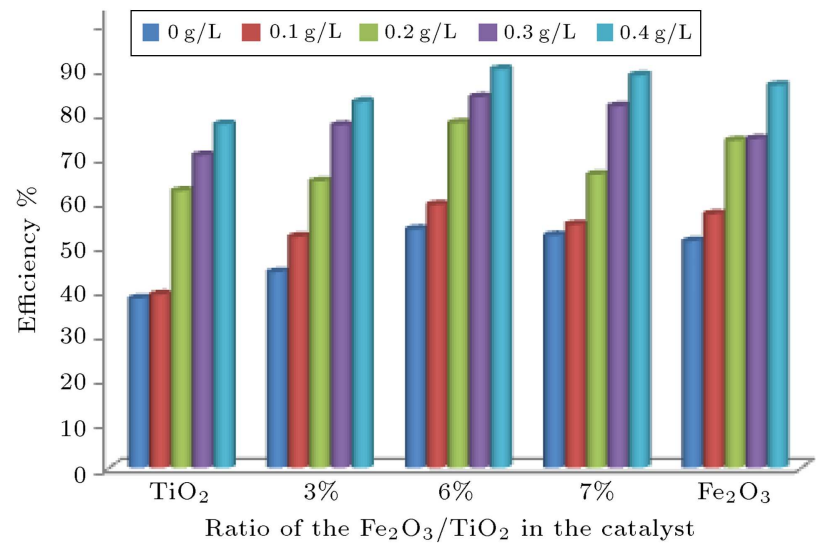

Figure 4. Degradation efficiency of furfural catalyzed by photocatalysts doped with different dosage of iron ions in different $\mathrm{H}_{2} \mathrm{O}_{2}$ concentrations. Time: 2 hours, the initial concentration of furfural: $0.3 \mathrm{~g} / \mathrm{L}$.

result is similar to that of a previous study reported by Wang et al. [17], which indicates that the photocatalytic activities of $\mathrm{Fe}_{2} \mathrm{O}_{3} / \mathrm{TiO}_{2} /$ zeolite photocatalysts strongly depend on the concentration of iron ions. It was observed that the hybridized catalysts were more effective than pure iron and titanium catalysts. It was due to combination of two semiconductors that creates a new energy gap laid between the band gap energies of single semiconductors [22]. The effect of hydrogen peroxide on furfural degradation efficiency is shown in Figure 5. With increasing $\mathrm{H}_{2} \mathrm{O}_{2}$ dosage, from 0 to $0.4 \mathrm{~g} / \mathrm{L}$, the efficiency increases. For the 


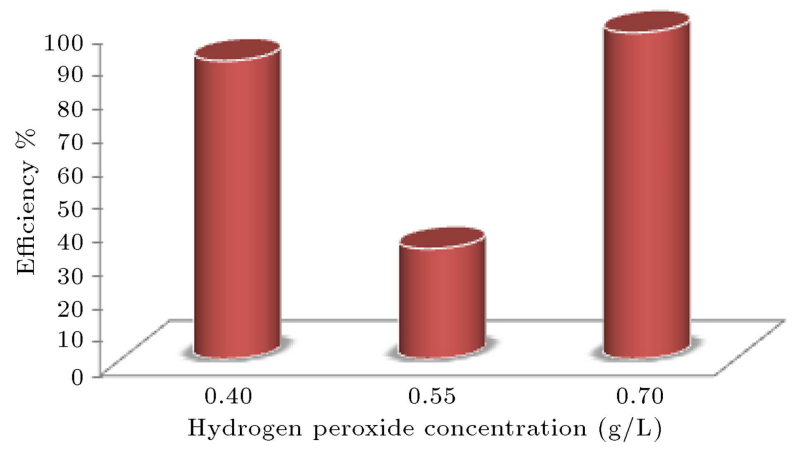

Figure 5. Effects of hydrogen peroxide concentration on the furfural degradation efficiency.
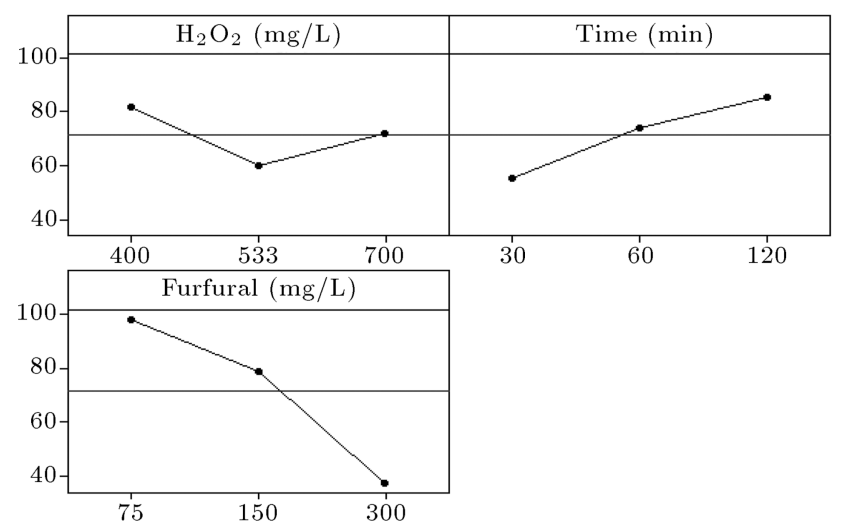

Figure 6. Main effects of plot for efficiency\%.

higher $\mathrm{H}_{2} \mathrm{O}_{2}$ dosages, another Taguchi design was utilized. By increasing $\mathrm{H}_{2} \mathrm{O}_{2}$ dosage from 0.4 to 0.55 $\mathrm{g} / \mathrm{L}$, the efficiency decreases, then increases within 0.55 to $0.7 \mathrm{~g} / \mathrm{L}$, and this trend is shown in Figure 5 . The main effects of the plot of this design are shown in Figure 6. According to this plot, the efficiency increases by increasing time and decreasing the furfural concentration.

In the second design, we used Taguchi method again in which initial $\mathrm{pH}$ value of furfural solution, concentration of furfural, dosage of the photocatalyst, and irradiation time were considered as the effective parameters; other factors, such as temperature, light intensity, and $\mathrm{H}_{2} \mathrm{O}_{2}$ content, were kept constant. The four factors in three different levels within the optimum operating condition $(6 \%$ catalyst and $400 \mathrm{mg} / \mathrm{L}$ hydrogen peroxide) were studied. The levels of the parameters are presented in Table 3 .

Table 3. Factors and selected levels.

\begin{tabular}{cccc}
\hline pH & $\begin{array}{c}\text { Contact } \\
\text { time } \\
(\mathbf{m i n})\end{array}$ & $\begin{array}{c}\text { Concentration of } \\
\text { furfural } \\
(\mathbf{m g} / \mathbf{L})\end{array}$ & $\begin{array}{c}\text { Dosage of } \\
\text { catalyst } \\
(\mathbf{g} / \mathbf{L})\end{array}$ \\
\hline 2 & 30 & 75 & $0 / 5$ \\
7 & 60 & 150 & 1 \\
10 & 120 & 300 & $1 / 5$ \\
\hline
\end{tabular}

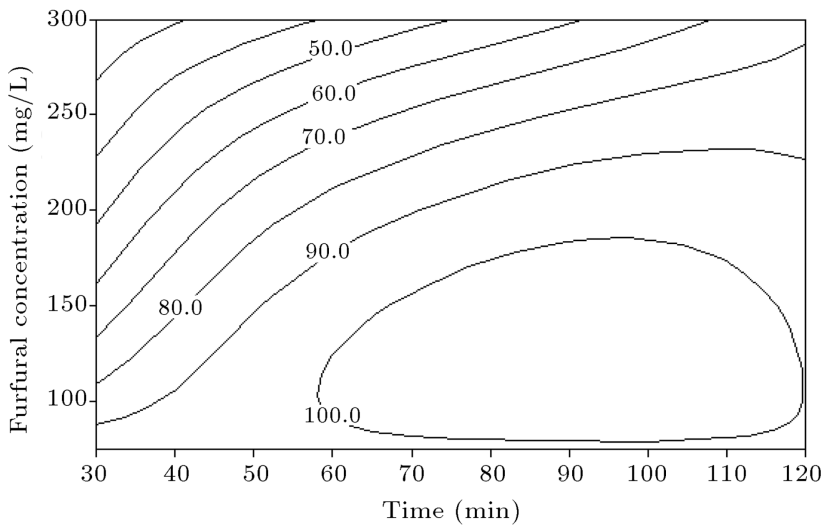

Figure 7. The contour plot of efficiency for furfural concentration versus time.

\subsubsection{Effect of the furfural initial concentration}

For examination of the furfural initial concentration, the experiments were conducted in three levels of furfural concentrations: 75,150 , and $300 \mathrm{mg} / \mathrm{L}$. The contour plot of efficiency versus the furfural concentration and time is shown in Figure 7 . It can be observed that the degradation efficiency of furfural decreases by increasing the initial concentration to values above $300 \mathrm{mg} / \mathrm{L}$. By increasing the furfural content, more furfural molecules are adsorbed onto the surface of the nanophotocatalyst, and the active sites of the catalyst are reduced. Therefore, by enhancement of the occupied spaces on the catalyst surface, the generation of hydroxyl radicals decreases. Also, increasing the concentration of furfural can lead to decreasing the number of photons that reaches the surface of the nanophotocatalyst. Therefore, the UV light is absorbed by the molecules of furfural, and the stimulation of nanophotocatalyst particles by photons is reduced. These results are in accordance with those of previous studies $[9,23]$.

\subsubsection{Effect of the contact time}

To study the effect of contact time, the experiments were performed in $0.5,1$, and 2 hour periods. Figure 8 illustrates that by increasing the contact time, the

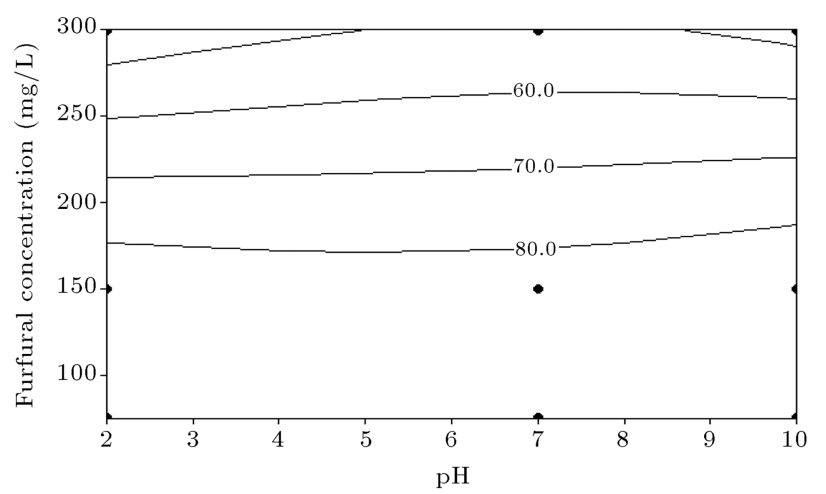

Figure 8. Contour plot of efficiency for furfural concentration versus $\mathrm{pH}$. 
efficiency increases due to the free radical molecules of furfural and have more opportunities to attack and destroy the furfural molecules. The efficiency of above $98 \%$ was achieved at contact time of about 2 hours. These results are in accordance with those of previous studies $[2,3,8,9]$.

\subsubsection{Effect of the $p H$}

Additional experiments were performed to determine the most effective initial $\mathrm{pH}$ for furfural degradation. The effect of solution $\mathrm{pH}$ (in the ranges of 2-10) on the degradation efficiency of furfural was investigated. The furfural solutions were adjusted to reach the desired $\mathrm{pH}$ by addition of sulphuric acid and/or sodium hydroxide. As shown in Figure 8, the degradation efficiency of furfural is higher in $\mathrm{pH}$ ranges of 7 to 10 .

In the initial acidic pHs, high amount of conjugated base was added to the solution. The sulfate anion, $\mathrm{SO}_{4}^{2-}$, reacts with hydroxyl radicals leading to the formation of inorganic radical ions. These inorganic radical anions show much lower reactivity than hydroxyl radical and do not take part in the furfural degradation. There is also a drastic competition between furfural and anions with respect to $\mathrm{OH}^{-}$. Hence, an increase in $\mathrm{pH}$ leads to an increase in the degradation efficiency. As the results show, there is a decrease in the removal efficiency at $\mathrm{pH}$ values higher than 7 . Researchers suggested that at high concentrations of $\mathrm{OH}^{-}$( $\mathrm{pH}$ above 9), two reactions may take place leading to the deactivation of hydroxyl radical [9,24]. First, $\mathrm{H}_{2} \mathrm{O}_{2}$. and $\mathrm{HO}_{2}$. radicals form due to the reaction of hydroxyl radical with $\mathrm{OH}^{-}$. The reactivity of these radicals with organic materials is less than $\mathrm{OH}^{-}$[25]. Second, due to the presence of high amounts of $\mathrm{OH}^{-}$radicals, the radical-radical reactions take place at higher $\mathrm{pH}$ values [26]. The deactivation of $\mathrm{OH}^{-}$radicals in high $\mathrm{pH}$ values has been previously reported [25]. Also, at neutral $\mathrm{pH}$, the adsorption of furfural is favored on nano-particle's surface, and the degradation is increased. The same results were reported by Houas et al. and Ahmadi et al. [6,27]. However, in this study, the $\mathrm{pH}$ changes did not have significant effect on the efficiency. Moreover, due to $\mathrm{H}^{+}$cation production, the final solution was acidic in all the experiments.

\subsubsection{Effect of the catalyst dosage}

The initial efficiency of photocatalytic degradation of many pollutants is a function of the photocatalyst dosage [28]. The effect of photocatalyst amount on the degradation of furfural was studied in a series of experiments, and the result of degradation efficiencies versus catalyst dosages was presented in Figure 9. It is observed that the amount of catalyst has insignificant effect on the degradation efficiency of furfural.

\subsection{The results of confirmatory tests}

\subsubsection{The result of HPLC analysis}

To evaluate the extent of degradation and mineralization of furfural, a HPLC analyzer was used. For furfural analysis by HPLC analyzer, first, a calibration curve was prepared which is shown in Figure 10. The results of this analysis are shown in Table 4 . These results confirm those for furfural degradation during the photocatalytic oxidation reactions, measured by spectrophotometric technique.

\subsubsection{The result of $C O D$ analyzer}

To investigate the toxicity of the photocatalyzed solution, the COD analysis of furfural before and after the reaction was determined, which is shown in Table 4 . A significant decrease in the solution COD to above $55 \%$

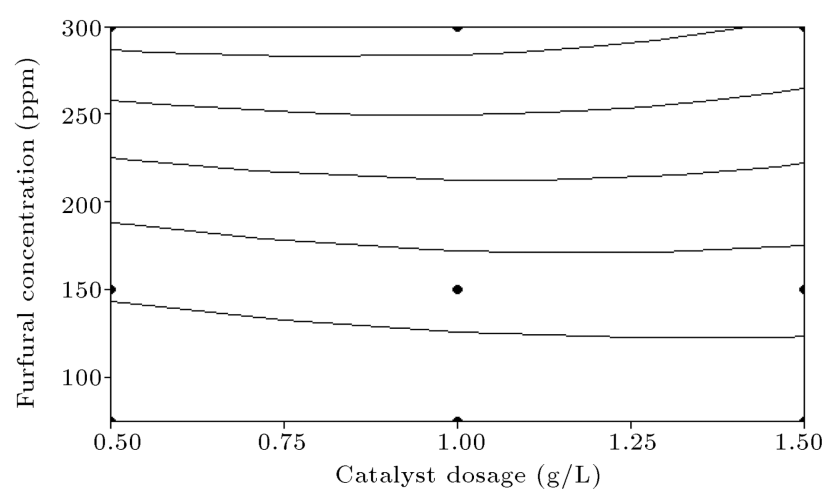

Figure 9. Effect of catalyst dosage on the degradation efficiency.

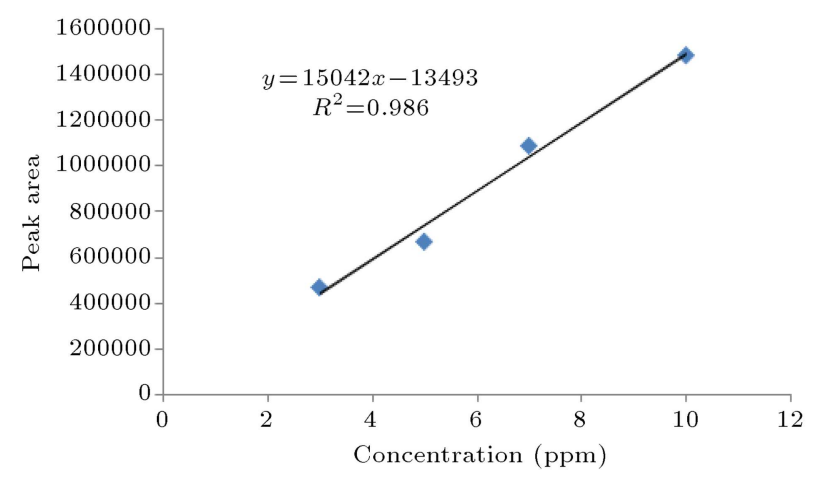

Figure 10. Calibration curve of furfural achieved by HPLC analyzer.

Table 4. Concentration of furfural before and after phtocatalytic reaction.

\begin{tabular}{ccc}
\hline Type of device & $\begin{array}{c}\text { Concentration } \\
\text { of furfural } \\
\text { before reaction } \\
(\mathbf{m g} / \mathbf{L})\end{array}$ & $\begin{array}{c}\text { Concentration } \\
\text { of furfural } \\
\text { after reaction } \\
(\mathbf{m g} / \mathbf{L})\end{array}$ \\
\hline Spectrophotometer & 100 & 4 \\
HPLC & 100 & 5.5 \\
COD & 108 & 48 \\
\hline
\end{tabular}


is observed. These results confirm the spectrophotometer analysis.

\section{Conclusions}

According to our research, photocatalytic degradation is an inexpensive, easy to run, effective and fast process by which the removal efficiencies more than $95 \%$ could be achieved in only 120 minutes. Furfural can be more efficiently degraded by $\mathrm{TiO}_{2}$ and $\mathrm{Fe}_{2} \mathrm{O}_{3}$ incorporated clinoptilolite zeolite in the presence of UV radiation. The slurry photoreactor used in this work appeared to be a proper system due to its capability of efficiently distributing catalyst through the contaminated water. An important advantage of this method is using a very small amount of photocatalyst $(0.5 \mathrm{~g} / \mathrm{L})$. It reduces the consumption of photocatalyst and photons due to the reduction of scattering and finally lessens the contamination of the environment. Besides, maximum photodegradation efficiency was obtained when the experiments were performed in the neutral to alkaline solutions. Furthermore, the experiments were more efficient in the low initial concentrations of furfural. The effectiveness of these processes was indicated by confirmatory tests to evaluate the removal of furfural. The XRD and SEM analysis on the photpcatalyst revealed that the method adopted to immobilize titanium dioxide and iron nano-particles on the zeolite was suitable for this purpose. No serious structural changes were detected in the titanium dioxide and iron particles, and the distribution of these nanoparticles on the zeolite surface was uniform.

\section{Acknowledgements}

The authors would like to express their thanks to the laboratory staff of the Department of Chemical Engineering and Islamic Azad University of Shahreza, for their collaboration.

\section{References}

1. Borghei, S.M. and Hosseini, S.N. "Comparison of furfural degradation by different photooxidation methods", Chemical Engineering Journal, 139(3), pp. 482488 (2008).

2. Kang, C.L., Tang, X.J., Jiao, X.Q., Guo, P., Quan, F.M. and Lin, X.Y. "Degradation of furfural by UV/O $\mathrm{O}_{3}$ technology", Chemical Research in Chinese Universities, 25(4), pp. 451-454 (2009).

3. Tang, X., Guo, Z., Xue, H., Guo, X. and Kang, C. "Degradation of furfural by $\mathrm{UV} / \mathrm{O}_{3} / \mathrm{H}_{2} \mathrm{O}_{2}$ technology", In Bioinformatics and Biomedical Engineering, (iCBBE) 5th International Conference on IEEE., pp. 1-4 (2011).

4. Kabra, K., Chaudhary, R. and Sawhney, R.L. "Treatment of hazardous organic and inorganic compounds through aqueous-phase photocatalysis: a review". Industrial \& Engineering Chemistry Research, 43(24), pp. 7683-7696 (2004).

5. Fernández, P., Blanco, J., Sichel, C. and Malato, S. "Water disinfection by solar photocatalysis using compound parabolic collectors", Catalysis Today, 101(3), pp. 345-352 (2005).

6. Ahmadi, F., Zarrin, L., Sharifnia, S. and Hosseini, S.N. "Analyzed and proposed mechanism of photocatalytic degradation of furfural at $\mathrm{TiO}_{2}$ nano-particles by HPLC-UV and LC-mass methods", Journal of Liquid Chromatography \& Related Technologies., 37(12), pp. 1750-1762 (2014).

7. Nanoti, A., Gupta, P., Dasgupta, S., Garg, M.O. and Goswami, A.N. "Process studies for development of adsorption technology for furfural recovery from waste water", Environmental Progress, 27(3), pp. 308-312 (2008).

8. Faramarzpour, M., Vossoughi, M. and Borghei, M. "Photocatalytic degradation of furfural by titania nanoparticles in a floating-bed photoreactor", Chemical Engineering Journal, 146(1), pp. 79-85 (2009).

9. Nezamzadeh-Ejhieh, A. and Moeinirad, S. "Heterogeneous photocatalytic degradation of furfural using NiSclinoptilolite zeolite", Desalination, 273(2), pp. 248257 (2011).

10. Hosseini, L., Ghafurian, N., Hosseini, S.N. and Hassanzadeh, S.M. "Immobilization of $\mathrm{TiO}_{2}$ on leca granules for photocatalytic degradation of furfural", Caspian Journal of Applied Sciences Research, 3(8), pp. 23-30 (2014).

11. Zhang, D., Wang, B., Zhang, L.Y. and Wang, M. "Synthesis of strontium titanate microtubule and their photocatalytic activity for degradation of furfural in aqueous solutions", Journal of Advanced Oxidation Technologies, 18(2), pp. 221-226 (2015).

12. Mousavi-Mortazavi, S. and Nezamzadeh-Ejhieh, A. "Supported iron oxide onto an Iranian clinoptilolite as a heterogeneous catalyst for photodegradation of furfural in a wastewater sample", Desalination and Water Treatment, 57(23), pp. 10802-10814 (2016).

13. Veisi, F., Zazouli, M.A., Ebrahimzadeh, M.A., Charati, J.Y. and Dezfoli, A.S. "Photocatalytic degradation of furfural in aqueous solution by N-doped titanium dioxide nanoparticles", Environmental Science and Pollution Research, 23(2), pp. 1-15 (2016).

14. Soltan, S., Jafari, H., Afshar, S. and Zabihi, O. "Enhancement of photocatalytic degradation of furfural and acetophenone in water media using nano$\mathrm{TiO}_{2} / \mathrm{SiO}_{2}$ deposited on cementitious materials", $W a$ ter Science and Technology, wst 2016343 (2016).

15. Esmaili-Hafshejani, J. and Nezamzadeh-Ejhieh, A. "Increased photocatalytic activity of $\mathrm{Zn}$ (II)/Cu (II) oxides and sulfides by coupling and supporting them onto clinoptilolite nanoparticles in the degradation of benzophenone aqueous solution", Journal of Hazardous Materials, 316, pp. 194-203 (2016). 
16. American Public Health Association, Standard Methods for the Examination of Water and Sewage (1915).

17. Wang, C., Shi, H. and Li, Y. "Synthesis and characteristics of natural zeolite supported $\mathrm{Fe}^{3+}-\mathrm{TiO}_{2}$ photocatalysts", Applied Surface Science, 257(15), pp. 6873-6877 (2011).

18. Gottardi, G. and Galli, E. "Natural zeolites", p. 409, Berlin: Springer-Verlag (1985).

19. Lee, H.C., Woo, H.C., Chung, S.H., Kim, H.J., Lee, K.H. and Lee, J.S. "Effects of metal cation on the skeletal isomerization of 1-butene over clinoptilolite", Journal of Catalysis, 211(1), pp. 216-225 (2002).

20. Arimi, A., Farhadian, M., Nazar, A.R.S. and Homayoonfal, M. "Assessment of operating parameters for photocatalytic degradation of a textile dye by $\mathrm{Fe}_{2} \mathrm{O}_{3} / \mathrm{TiO}_{2} /$ clinoptilolite nanocatalyst using Taguchi experimental design", Research on Chemical Intermediates, 42(5), pp. 4021-4040 (2016).

21. Li, F., Jiang, Y., Yu, L., Yang, Z., Hou, T. and Sun, S. "Surface effect of natural zeolite (clinoptilolite) on the photocatalytic activity of $\mathrm{TiO}_{2} "$, Applied Surface Science, 252(5), pp. 1410-1416 (2005).

22. Mohammadyari, P. and Nezamzadeh-Ejhieh, A. "Supporting of mixed ZnS-NiS semiconductors onto clinoptilolitenano-particles to improve its activity in photodegradation of 2-nitrotoluene", RSC Advances, 5(92), pp. 75300-75310 (2015).

23. Pouretedal, H.R., Norozi, A., Keshavarz, M.H. and Semnani, A. "Nanoparticles of zinc sulfide doped with manganese, nickel and copper as nanophotocatalyst in the degradation of organic dyes", Journal of Hazardous Materials, 162(2), pp. 674-681 (2009).

24. Ejhieh, A.N. and Khorsandi, M. "Photodecolorization of eiochrome black T using NiS-P zeolite as a heterogeneous catalyst", Journal of Hazardous Materials, 176(1), pp. 629-637 (2010).

25. Kasiri, M.B., Aleboyeh, H. and Aleboyeh, A. "Degra- dation of acid blue 74 using Fe- $\mathrm{ZSM}_{5}$ zeolite as a heterogeneous photo-fenton catalyst", Applied Catalysis B: Environmental, 84(1), pp. 9-15 (2008).

26. Ashraf, S.S., Rauf, M.A. and Alhadrami, S. "Degradation of methyl red using fenton's reagent and the effect of various salts", Dyes and Pigments, 69(1), pp. 74-78 (2006).

27. Houas, A., Lachheb, H., Ksibi, M., Elaloui, E., Guillard, C. and Herrmann, J.M. "Photocatalytic degradation pathway of methylene blue in water", Applied Catalysis B: Environmental, 31(2), pp. 145157 (2001).

28. Goncalves, M.S., Oliveira-Campos, A.M., Pinto, E.M., Plasência, P. and Queiroz, M.J.R. "Photochemical treatment of solutions of azo dyes containing $\mathrm{TiO}_{2}$ ", Chemosphere, 39(5), pp. 781-786 (1999).

\section{Biographies}

Zakie Esmaili received the BSc degree in Chemical Engineering from Bahonar University of Kerman, the MSc degree in Chemical Engineering from Isfahan University, and she is now PhD student in Chemical Engineering at Isfahan University of Technology.

Ali Reza Solaimany Nazar is currently Associate Professor in the Chemical Engineering Department at University of Isfahan, Iran. His research interests are mainly asphaltene and wax deposition in reservoir and transportation line, adsorption and advanced oxidation process in water and wastewater treatment.

Mehrdad Farhadian is the Head of Environmental Research Institute at University of Isfahan, Isfahan, Iran. His main research interests include water and wastewater treatment and environmental engineering in the field of chemical engineering. 